\title{
No caminho da proteção ambiental: Ações para a saúde humana e ambiente na população campesina do Pantanal Mato-grossense, Brasil
}

\author{
Towards environmental protection: actions to human and \\ environment health in the peasant population of Pantanal in \\ Mato Grosso - Brazil
}

Marta Gislene Pignatti ${ }^{1}$

\begin{abstract}
Resumo
Este artigo discute, a partir das transformações históricas ocorridas no território de uma população rural autodenominada Povo de Joselândia, no interior do Pantanal Mato-grossense, situada no entorno de uma área de proteção ambiental, as ações de políticas públicas em saúde humana e ambiente realizada na área, no período de 2003 a 2013. Tomando como ponto de ancoragem a territorialização e desterritorialização do campesino brasileiro, cotejamos a discussão sobre a ação estratégica das instituições envolvidas com a comunidade desde a instalação da Reserva do Patrimônio Natural Particular (RPPN), em 1997, e das políticas públicas federais, estaduais e municipais e sobre o papel da ciência na área. Os moradores foram alijados do processo de uso e manejo da terra. Em 2007 essa população foi classificada como comunidade tradicional e foi garantida por lei a sua reprodução cultural. No cotidiano da assistência à saúde humana, a disputa entre estado e município resultou numa ausência da assistência médica regular por longos períodos, ficando a assistência restrita à medicina popular. O papel das pesquisas científicas tem sido arbitrar o que e quem pode manejar os recursos naturais na área, inviabilizando o modo de vida campesino.

Palavras-chave: proteção ambiental; população rural; serviços de saúde; ciência.

Abstract

This article discusses from the historic environment transformation of a rural self-styled population of people from Joselândia, in the Pantanal, located in the vicinity of a protected area; the actions of public policies on human and environment health held in the area between 2003 and 2013. Considering the territorialization and deterritorialization of the Brazilian peasant population, we compare the discussion on strategic action of the institutions involved in the community since the installation of the Private Natural Heritage Reserve (PRNP) in 1997 and of federal and local public policies; and the scientific influence in the area. The locals were priced out of the use and land management process. It was classified as traditional and guaranteed by law to their cultural community in 2007. In the daily routine of human health assistance, the dispute between the state and local level resulted in a lack of regular medical care for long periods being restricted to folk medicine. The role of scientific research resumes arbitrating what and who can manage natural resources in the area, preventing the peasant life style.
\end{abstract}

Keywords: environmental protection; rural population; health services; science.

${ }^{1}$ Grupo de Estudos Ambientais e Saúde do Trabalhador, Instituto de Saúde Coletiva, Universidade Federal de Mato Grosso (UFMT) - Cuiabá (MT), Brasil. Trabalho realizado na Universidade Federal de Mato Grosso (UFMT) - Cuiabá (MT), Brasil.

Endereço para correspondência: Marta Gislene Pignatti - Av. Fernando Correa Costa, s/n - Campus Cuiabá - CEP: 78090-000 - Cuiabá (MT), Brasil Email: martapignatti646@gmail.com

Fonte de financiamento: nenhuma.

Conflito de interesses: nada a declarar 


\section{INTRODUÇÃO}

Este artigo discute, a partir do território, as ações para a proteção ambiental (conservação/preservação) e saúde humana numa população campesina no interior do Pantanal Mato-grossense, moradora no distrito de Joselândia ${ }^{1}$, município de Barão de Melgaço, Mato Grosso, situada no entorno de uma Reserva Particular do Patrimônio Natural (RPPN-SESC Pantanal) $)^{2}$. Por outro lado, procura trazer à tona ações dos atores envolvidos nas políticas e arbitragem da ciência para, em nome da proteção ambiental, dificultar a reprodução do modo de vida campesino no interior do Pantanal.

As terras para o estabelecimento da Reserva Particular do Patrimônio Natural (RPPN) foram adquiridas pelo Serviço Social do Comércio (SESC) e estão situadas entre os paralelos 16, a 170 S, e 56 a, 570W, na parte norte do Pantanal Mato-grossense, com uma superfície de 106.307 hectares de área conservada. No seu entorno vivem e moram 2.483 pessoas, residentes em 592 domicílios distribuídos nas comunidades: sede, de São Pedro, Mocambo, Pimenteira, Retiro São Bento, Colônia Santa Isabel, Capoeirinha e Lagoa do Algodão. Essas comunidades estão interligadas por uma rede de parentesco consanguínea, afinidade e compadrio que lhes permite identificar o conjunto dos grupos por Povo de Joselândia ${ }^{1}$.

Após a promulgação do decreto 6.040/2007, elas foram classificadas como tradicionais pelo Ministério do Meio Ambiente e autodenominadas "Povo de Joselândia", caso em que o uso do território é garantido pela legislação vigente ${ }^{1-3}$. Constam também no mapeamento dos territórios e identidades do Estado de Mato Grosso realizado por Sato et al. ${ }^{4}$ como "povo pantaneiro."

A questão do direito à terra para preservação ambiental e/ou para utilização pela população tradicional traz para o debate os direitos sobrepostos e em que medida eles têm sido observados pelos atores das políticas públicas, no caso, inclusive pelos proprietários da Reserva Particular do Patrimônio Natural. As políticas públicas voltadas à proteção ambiental e à proteção da diversidade cultural frequentemente sobrepõem-se num mesmo território e a ciência e o direito são chamados para arbitrar a contenda, conforme apontam Mendes e Ferreira ${ }^{5}$.

Reportamo-nos a Milton Santos ${ }^{6}$, que distingue o território como recurso, prerrogativa dos atores hegemônicos, e o território como abrigo dos atores hegemonizados. Todo território é, ao mesmo tempo e obrigatoriamente, em diferentes combinações, funcional e simbólico, pois exerce-se domínio sobre o espaço tanto para realizar funções quanto para produzir significados. No caso da população campesina, os mecanismos de domínio, posse e titulação das terras ancestralmente utilizadas passaram por processo de apropriação individual e, em Mato Grosso, essas foram distribuídas a proprietários individuais nas décadas de 1960 e 1970 com a anuência e incentivo governamental, desrespeitando-se os direitos das comunidades tradicionais, indígenas e quilombolas ${ }^{7}$.

No ordenamento histórico do espaço, essa terra pertencia ao imemorial povo Bororo. A fundação do lugar pelo colonizador remonta ao século XIX, vinculada à formação de um campesinato no entorno das grandes usinas de açúcar que abasteciam com provisões alimentícias as embarcações que passavam rumo ao Rio Paraguai. Com o declínio desse comércio, esses campesinos foram fixando suas roças mais para o interior do Pantanal, entre os rios São Lourenço e Cuiabá ${ }^{1}$.

Na perspectiva da conservação e preservação da biodiversidade, mote da questão ambiental dos anos 1990, houve, por parte do governo brasileiro, um esforço para criação de parques e reservas em áreas naturais públicas e/ou privadas ${ }^{8}$. Como avaliou Diegues ${ }^{9}$, utilizou-se o modelo de parques norte-americano, com a expulsão de população humana das áreas.

No Sistema Nacional de Unidades de Conservação (SNUC) ${ }^{10}$, a RPPN pertence ao Grupo das Unidades de Uso Sustentável e o seu entorno é considerado zona de amortecimento na qual as atividades humanas estão sujeitas a normas e restrições específicas, com o propósito de minimizar os impactos negativos sobre a unidade. Também pode ser classificada como área de proteção ambiental com certo grau de ocupação humana, dotada de atributos abióticos, bióticos, estéticos ou culturais especialmente importantes para a qualidade de vida e o bem-estar das populações humanas, e tem como objetivos básicos proteger a diversidade biológica, disciplinar o processo de ocupação e assegurar a sustentabilidade do uso dos recursos naturais, sendo constituída por terras públicas ou privadas. No entanto, nas áreas onde a propriedade é privada, cabe ao proprietário estabelecer as condições para pesquisa e visitação pelo público.

$\mathrm{O}$ objetivo da $\mathrm{RPPN}^{2}$ seria: beneficiar a proteção da biodiversidade ecológica, promovendo a regulação ambiental, a preservação de recursos genéticos, a manutenção dos ciclos sazonais das águas e a proteção da beleza cênica de uma extensão de $1.060 \mathrm{~km}^{2}$ de Pantanal.

A articulação das ações de gestão das áreas protegidas, das terras indígenas e das terras ocupadas por remanescentes das comunidades dos quilombos estão indicadas para as políticas públicas nos três níveis de governo e com os segmentos da sociedade, inclusive: “[...] a promoção da participação, da inclusão social e do exercício da cidadania, buscando permanentemente o desenvolvimento social, especialmente para as populações do interior e do entorno das áreas protegidas [...]"11.

No entanto, a dupla classificação da comunidade de Joselândia como área de proteção ambiental e população tradicional implica numa luta por reconhecimento da posse da terra, cerne do capitalismo, gerando conflitos históricos, conforme Honneth ${ }^{12}$.

A luta pelo uso e posse do território necessário à reprodução do modo de vida tradicional é uma construção social sobre 
o espaço e a sua ocupação como propriedade física confere características de funcionamento não autônomo mas como locus da ocorrência de fenômenos que se relacionam. O território é a arena da oposição entre mercado e técnicas da produção, organização da produção, geografia da produção e sociedade civil e, desse modo, envolve, sem distinção, todas as pessoas. O território é suporte de redes que transportam as verticalidades, isto é, as regras e normas egoísticas e utilitárias, enquanto as horizontalidades levam em conta a totalidade dos atores e das ações ${ }^{6,13}$.

No ordenamento ligado à constituição e à transformação da natureza e nas determinações históricas relativas à constituição e à transformação das sociedades, o processo de territorialização e desterritorialização ${ }^{14}$ tem sido contínuo para grupos que foram alijados de terras ancestralmente ocupadas e que, em nome da proteção ambiental e propriedade privada, veem-se impossibilitados de manter seu modo de vida, ligado à agricultura familiar em área de pântano.

Nesse cenário de vida do "Povo de Joselândia" buscamos evidenciar algumas ações estratégicas das instituições governamentais e privadas na área, a prática dos atores envolvidos nas políticas públicas, tendo em vista a sobreposição dos direitos à terra e direitos socioambientais.

\section{ESTRATÉGIAS METODOLÓGICAS}

A perspectiva teórica se pautou na teoria da ação comunicativa de Habermas ${ }^{15}$ consubstanciada e discutida por Rivera ${ }^{16}$ na perspectiva do planejamento social. Tomando as ações realizadas pelas instituições privadas ou públicas na área, baseadas na racionalidade estratégica que se concentra no processo de escolha de fins como a conservação ou o respeito ao modo de vida campesino e em ações instrumentais que se concentram nas tarefas técnicas de controle (ou da apropriação) da natureza e dos estados de coisas que fazem parte do mundo objetivo e são padronizadas, o estudo de caso foi realizado na área, no período de 2003 a 2013.

Em sua acepção mais operacional, política é entendida como ações, práticas, diretrizes políticas, fundadas em leis e empreendidas como funções de Estado por um governo para resolver questões gerais e específicas da sociedade. Em termos político-administrativos, o desenvolvimento de uma sociedade resulta de decisões formuladas e implementadas pelos governos do Estado nacional, pelos subnacionais e supranacionais, em conjunto com as demais forças vivas da sociedade. Em seu conjunto, essas decisões e ações de governo e de outros atores sociais constituem o que se conhece pelo nome genérico de políticas públicas ${ }^{17}$.

Nossa análise foi ancorada em apontamentos da legislação ambiental, dos direitos das comunidades tradicionais e da releitura da produção de dissertações e relatórios de pesquisa no período.

Foram entrevistados o técnico responsável por desenvolver ações com a comunidade do entorno, contratado pelos proprietários da RPPN, os gestores, Secretário Municipal de Saúde do município de Barão de Melgaço e os da Fundação Nacional de Saúde (FUNASA - regional Mato Grosso), e realizada pesquisa de opinião com alguns moradores sobre as ações desenvolvidas pelos governos e técnicos do SESC. Contamos também, no período de 2003 a 2013, com dois informantes: o motorista da equipe e o agente comunitário de saúde local.

Salientamos que, após embates com o Comitê de Ética em Pesquisa em Saúde, os quais sublinhavam a responsabilidade pelas informações, sob "tutela" da administração municipal e/ou de alguma associação local e da equipe que tratava a população como sujeitos autônomos, com autorização individual e/ou familiar, a pesquisa foi aprovada, sob n. 252/CEP - Hospital Universitário Júlio Muller, Universidade Federal de Mato Grosso.

Participaram do projeto alunos da graduação, como bolsistas de iniciação científica da área da saúde e assistência social, e mestrandos do Programa de Pós-graduação em Saúde Coletiva do Instituto de Saúde Coletiva da Universidade Federal de Mato Grosso. As dissertações desses mestrandos podem ser acessadas no site do programa.

\section{SOBRE O USO DO TERRITÓRIO}

No âmbito interno da formação social do "Povo de Joselândia", a terra era considerada um bem comum partilhado entre as famílias, não havendo cercas. No entanto, também adentraram os pantanais donos de usinas, comerciantes, gente de posse que, ao se instalar, tratou de tomar "nacos" maiores de terra para iniciar o jogo e estabelecer atividades usando a terra para a pecuária extensiva. Algumas famílias tornaram-se empregadas dos fazendeiros, deixando de exercer a agricultura familiar ou compatibilizando as duas. Outros voltaram-se para a reprodução do modo de vida. Filhos, filhas, netos partilharam a mesma identidade e aprendizado com os pais na lida com a terra ${ }^{1}$.

Heidrich $^{13}$ reitera que o território é também definido pela apropriação das condições naturais e físicas. Nas atividades de redistribuição das terras para o plantio não havia cerca e nem mediadores governamentais, como aponta $\operatorname{Serres}^{18}$ (p. 67), no Egito antigo:

[...] as enchentes do Nilo inundavam os limites dos campos cultiváveis no vale aluvial que o rio fecundava: por conta da estiagem, funcionários reais, chamados herpdonaptas, agrimensores ou geômetras, mediam novamente as terras revolvidas pelo limo e o lodo, para redistribuí-la ou distribuir partes delas. A vida recomeçava. Todos voltavam a trabalhar.

O fato de a comunidade se situar em área de inundação confere características peculiares ao uso do território: à época das cheias havia um mecanismo de solidariedade entre os 
moradores no uso de residências e na transferência dos animais para as partes mais altas e/ou ida de moradores para cidades, temporariamente, retornando-se à área para a plantação de culturas agrícolas no lodo, principalmente milho e feijão.

O Povo de Joselandia foi sendo pressionado tanto por questões de mudanças no ritmo da inundação quanto pela apropriação individual por fazendas e, posteriormente, por restrições ao uso do território, pelo estabelecimento, em 1997, da reserva de conservação ambiental na apropriação privada dos espaços anteriormente ocupados, reduzindo-se ainda mais o espaço para a reprodução do modo de vida campesino.

A compra das fazendas nas quais parte dos campesinos completava a renda para o estabelecimento da reserva resultou na expulsão desses moradores e concentrou a população numa vila no entorno. Por outro lado, a organização das relações internas também se desarranjou, levando algumas famílias a abandonar a "lida com a terra", estabelecer-se como pequenos comerciantes ou migrar para as cidades. Outros, mesmo com dificuldades para manter o modo de vida baseado na agricultura familiar, se afastaram do circuito comercial da vila e se autodenominaram "fracos", mantendo suas roças, conforme Pignatti et al. ${ }^{19}$.

Nessa questão, sem mediadores governamentais e políticas públicas que garantissem a posse do território e o modo de vida da comunidade, outras restrições ao uso do território foram sendo impostas aos moradores pelo modelo de preservação e conservação ambiental adotado nos anos 1990, com a exclusão de população da área. Estabelece-se assim uma nova relação entre a reserva e a população local. Terra com preservação da biodiversidade natural e culturas agrícolas familiares não são consideradas compatíveis. A noção de "atraso" permeia a cultura da enxada, da sobrevivência das populações campesinas ${ }^{20}$. O mito moderno da natureza intocada também permeia alguns grupos sociais.

A dupla conotação do território, material e simbólica, parece etimologicamente tão próxima de terra-territorium quanto de terreo-territor (terror, aterrorizar), ou seja, relaciona-se com a dominação da terra e com a inspiração do terror, do medo, especialmente para aqueles que, com essa dominação, ficam alijados da terra, ou são impedidos de entrar no "territorium"13.

No caso, os moradores são impedidos de entrar na área de preservação/conservação ambiental, onde outrora, à época da inundação, deixavam seus pequenos rebanhos de gado, e alijados inclusive da possibilidade de desfrutar da beleza cênica da área, reservada para quem pode "pagar". Ainda, poucos são arregimentados para o combate aos incêndios, à época da seca. Hoje os animais da reserva invadem o espaço da comunidade e se alimentam do pequeno rebanho de gado, num crescimento exponencial da população animal no topo da cadeia alimentar, cujo único controle se fazia pela caça. Polêmica ainda não resolvida pelos pesquisadores ambientalistas.
A comunidade em questão esteve até os anos 1990 "esquecida" no circuito das políticas públicas e sociais, como outros grupos campesinos brasileiros ${ }^{21}$. A principal questão posta no jogo era a indenização para quem estava no interior da área sem escritura. De quem era a responsabilidade? Ao mesmo tempo, para o estabelecimento da RPPN havia necessidade de um plano de recuperação, conservação e preservação da área. Pesquisadores do Brasil todo foram requisitados para o inventário da fauna, flora e outros. E a população humana? Deveria ser retirada e foi arregimentada para exercer algumas atividades na reserva, como empregados contratados. Para o atendimento de outras demandas, foram encaminhados aos poderes públicos municipais.

\section{Ações de políticas públicas}

Até o estabelecimento da RPPN, uma das formas de acesso às políticas públicas se dava pelo recebimento da aposentadoria rural. A capacidade de o grupo acessar as políticas sociais veio como uma "benesse" de um deputado: a aposentadoria rural era entregue mensalmente para os aposentados, via aérea, em meio a uma feira-festa popular. O dinheiro trouxe para os moradores mais velhos mais respeito e cuidado por parte da família.

Também iniciaram-se no período as intervenções para saneamento básico, principalmente abastecimento de água. Em 1998, por projeto financiado pela Fundação Nacional de Saúde (FUNASA), a prefeitura municipal de Barão de Melgaço recebeu recursos financeiros para prover a vila com abastecimento de água. No entanto, o utilizou apenas para fazer um poço e abastecer a escola da vila com água potável. Foi preciso mediação judicial para que a prefeitura canalizasse a água para a comunidade, no ano de 2006.

No âmbito da assistência à saúde foi inaugurada em 2000 uma Unidade de Saúde, como um projeto estadual. Divergências com o poder municipal deixaram a comunidade sem equipe de saúde por anos, sendo que os moradores buscavam a assistência em outros municípios, deslocando-se por meio de barcos, aluguel de caminhões e/ou, em caso de emergência, por avião (pagamento cotizado entre eles).

A demanda, quando do início dos trabalhos de pesquisa da nossa equipe na área, em 2003, tanto por parte do município como dos proprietários da RPPN, foi para que a universidade se responsabilizasse pela assistência médica à comunidade, num misto de transferência de responsabilidade assistencial e descaso, gerando também essa expectativa na própria comunidade.

As pesquisas realizadas na área da saúde humana foram publicadas de forma a abranger os principais resultados sob o título Saúde e Ambiente: Lugar da doença e doença do lugar na população do entorno da RPPN SESC Pantanal22. Observou-se ainda que havia uma rede de apoio comunitário no atendimento aos "doentes", formada pelo agente comunitário de saúde e por benzedeiros(as) locais, e uma relação mercantilista nas 
emergências, consubstanciada pelo pagamento do transporte para os prontos-socorros das cidades próximas.

No caso de infraestrutura, através do projeto Luz do Campo, em 2005 foi instalada uma rede de energia elétrica. Realizaram-se também sorteio de casas para alguns moradores e melhorias no acesso via estrada, que funciona nos períodos de seca. O projeto foi capitaneado como obra do governador do estado, conforme moradores: "o único governador que esteve na comunidade e trouxe a energia elétrica."

Em relação às ações do governo municipal e/ou vereadores do local, os moradores referiram que: "só resolvem quando querem; são representantes, mas não fazem nada; dizem que fazem alguma coisa; nós não temos prefeito, não temos nada." Tais falas reforçam a sensação de abandono ou de não reconhecimento moral das necessidades do grupo.

Verificamos que a capacidade de acesso desse grupo é limitada e que ações pontuais são realizadas para alcançar objetivos definidos pelas instituições, beneficiando "individualmente" famílias com maior inserção no jogo clientelista da política pública. Ao mesmo tempo, há uma resistência silenciosa: a não adesão aos projetos compensatórios propostos pelo Serviço Social do Comércio no Pantanal. Há participação pontual de alguns grupos da comunidade, sem que esses projetos, no entanto, sejam apropriado como deles: É projeto do SESC. A não adesão pode ter várias causas, entre elas o distanciamento dos projetos em relação à cultura local.

\section{Do direito e ciência}

Se a justiça tem competência para conhecer a causa e a justeza é competente para conhecer a coisa, o direito diz respeito a um conjunto de regras universais relacionadas à natureza humana $\mathrm{e}$ deve ser fonte de leis positivas. No domínio jurídico, a natureza humana adquire um estatuto bem próximo ao das ciências: tem todos os direitos, porque funda o direito ${ }^{18}$. No entanto, o projeto moderno julgava possível o desenvolvimento harmonioso da regulação e da emancipação e a racionalização completa da vida individual e coletiva, as quais, com o tempo, mostraram-se incompatíveis ${ }^{23}$.

No Brasil, a regulação sobre os direitos das comunidades tradicionais ao uso do território foi estabelecida em $2006^{11}$. Nela estão colocadas, como definições:

Povos e Comunidades Tradicionais: Grupos culturalmente diferenciados e que se reconhecem como tais, que possuem formas próprias de organização social, que ocupam e usam territórios e recursos naturais como condição para sua reprodução cultural, social, religiosa, ancestral e econômica, utilizando conhecimentos, inovações e práticas gerados e transmitidos pela tradição.

Na Política Nacional de Desenvolvimento Sustentável dos Povos e Comunidades Tradicionais ${ }^{11}$ estão previstas formas de ações intersetoriais, integradas, coordenadas e sistemáticas para:
[...] o reconhecimento, a valorização e o respeito à diversidade socioambiental e cultural dos povos e comunidades tradicionais, levando-se em conta, dentre outros aspectos, os recortes etnia, raça, gênero, idade, religiosidade, ancestralidade, orientação sexual e atividades laborais, entre outros, bem como a relação desses em cada comunidade ou povo, de modo a não desrespeitar, subsumir ou negligenciar as diferenças dos mesmos grupos, comunidades ou povos ou, ainda, instaurar ou reforçar qualquer relação de desigualdade.

Hoje, a perspectiva do poder público local seria alçar a comunidade como atração "turística", principalmente nas festas religiosas tradicionais a São Pedro, sendo a vila invadida por bares e vendedores de toda parte do estado. Quanto às atividades relacionadas à agricultura familiar não há fomento e nem interesse no seu desenvolvimento, a não ser enquadradas em propostas relacionadas com projetos considerados pelos atores políticos como práticas que não interfiram no uso do solo: criação de abelhas, borboletas, horta e outras atividades artesanais padronizadas como fabricação caseira de compostas, sabonetes etc.

$\mathrm{Na}$ área em questão entrou em cena no ano de 2001 o Programa de Pesquisa Ecológica de Longa Duração (PELD) Pantanal Norte, formado por pesquisadores da Universidade Federal de Mato Grosso, inclusive o subprojeto 19: Vigilância e promoção da saúde da população do entorno da RPPN, sob nossa coordenação $0^{24}$.

O programa representa uma iniciativa do governo federal de articular, desde 1999, uma rede de sítios de referência para a pesquisa científica no tema Ecologia de Ecossistemas. Através do PELD, o CNPq fomenta a geração de conhecimento qualificado sobre os nossos ecossistemas e a biodiversidade que abrigam, contando com apoio financeiro do Ministério da Ciência, Tecnologia e Inovação (MCTI) e de 11 fundações estaduais de amparo à pesquisa, numa rede PELD com 30 sítios de pesquisa distribuídos em diversos ecossistemas ${ }^{25}$.

O Sítio 12 do PELD Pantanal Norte, composto inicialmente por um conjunto de 16 subprojetos distribuídos entre as duas principais áreas de atuação: o contexto ambiental e o contexto social, foi alocado na Reserva Particular do Patrimônio Natural - RPPN, por ela apresentar infraestrutura adequada a estudos científicos. O controle do fogo e a ausência do gado tornam a área ideal para estudos comparativos da dinâmica do ecossistema realizados em áreas não protegidas ${ }^{24}$.

Por outro lado, o cenário social no seu entorno era pouco estudado, compondo-se de uma população campesina, historicamente capaz de suportar as grandes alterações às quais o ambiente estava sujeito entre os períodos de seca e cheia. Houve um considerável movimento de evasão rural em direção a municípios fora da planície pantaneira e mudanças na dinâmica social associadas à instalação de fazendas e da própria RPPN que levaram a população local de um "tempo de fartura" a um "tempo de ambição", com diferenças sociais marcantes 
internas à comunidade, no ciclo histórico de territorialização e desterritorialização ${ }^{14,24}$.

Nos anos de 2006 e 2007 foi realizada uma pesquisa-ação de abordagem eco-saúde com pouca adesão da comunidade, no diagnóstico do problema de contaminação da água e consequências à saúde humana, e dos gestores de saúde municipais e estadual, na sua resolução. A sensibilização para a ação da comunidade foi realizada através de oficinas na metodologia problematizadora com os professores da escola local e alguns membros da comunidade, produzindo-se uma cartilha para fins didáticos na própria escola ${ }^{26}$. As relações internas de poder no "tempo da ambição" trouxeram para a arena outros conflitos de interesse entre os "fracos", que continuaram com suas atividades agrícolas no Pantanal, e os "fortes", comerciantes, guardas-parque, funcionários públicos e vereadores, numa política de troca de favores clientelista característica da região, fragilizando a luta por reconhecimento dos direitos ao uso da terra e acesso às políticas públicas. Também ficou clara a opção dos pesquisadores pela proteção da biodiversidade.

\section{CONSIDERAÇÕES SOBRE AS INJUSTIÇAS}

Enquanto a contenda entre proteção ambiental e respeito ao modo de vida tradicional ocorre no local, processos de degradação e poluições diversas vindas do planalto impactam negativamente sobre o Pantanal, de forma que, em longo prazo, mudanças substanciais poderão ocorrer no ambiente regional. O ciclo das águas está ameaçado pela construção de hidrelétricas nos rios que formam o Pantanal; por barreiras ou diques que impedem a profusão da água nas lagoas de reprodução dos peixes; pelo carreamento de fertilizantes, agrotóxicos e sedimentos utilizados pelas fazendas de cultivo agrícola; e pelo despejo in natura de esgoto e outros produtos das cidades; toda essa carga de rejeitos e dejetos banha a comunidade ${ }^{27,28}$.
Nesse sentido, potencializam-se os riscos socioambientais da comunidade, caracterizando-se como mais uma injustiça ambiental ${ }^{29}$. As injustiças ocorrem em dois ordenamentos do território: no aspecto físico da ocupação da terra, no acesso à água, no manejo do ambiente, incluindo-se a saúde humana, e no aspecto simbólico da reprodução do modo de vida da comunidade. O primeiro aspecto refere-se aos recursos naturais poluídos que banham a comunidade e à dificuldade de manutenção das roças, e o segundo, à capacidade de a comunidade acessar as oportunidades, à liberdade substantiva que as pessoas deveriam ter para levar sua vida, conforme $\operatorname{Sen}^{30}$.

As populações campesinas, alijadas do grande mercado do capital agroexportador e voltadas para a agricultura familiar de alimentos, se encontram numa tensão histórica: a luta pela terra e a dificuldade de sua manutenção. No primeiro caso, o movimento dos trabalhadores sem terra representa uma alternativa para os despossuídos e para os pequenos produtores na resistência à colonização do mundo da vida pelo dinheiro e poder.

Há contradição também entre a razão do juízo e razão do direito: um decreto federal regulamenta e reconhece a necessidade de titulação das terras de comunidades tradicionais e a legislação ambiental concede o direito privado às terras para a proteção da biodiversidade em uma área impactada por poluições diversas oriundas do planalto. Nesse duplo enquadramento, a luta política seria associar a proteção da biodiversidade ao grupo humano que até agora se mostrou conhecedor do ecossistema em que vive, manejando de forma sustentável seus recursos naturais.

Questões como essas nos fazem pensar: quem vai arbitrar o jogo da luta por reconhecimento e justiça? Quiçá as redes de mobilização alcancem os campesinos entre "árvores e esquecimento", na luta de resistência, nos sertões brasileiros ${ }^{21}$.

\section{REFERÊNCIAS}

1. Pignatti MG, Castro SPA. Fragilidade/resistência da vida humana em comunidades rurais do Pantanal Matogrossense - MT- Brasil. Cien Saude Colet. 2010;15(Supl.2):3221-32. http://dx.doi.org/10.1590/S141381232010000800027. PMid:21049163.

2. Serviço Social do Comércio Pantanal. Reserva Particular do Patrimônio Natural [Internet] [acesso em 2014 abr 10 ]. Disponível em http://www. sesc.pantanal

3. Brasil. Decreto 6.040, de 7 de fevereiro de 2007. Institui a Política Nacional de Desenvolvimento Sustentável dos Povos e Comunidades Tradicionais. Diário Oficial da União, Brasília, 8 de fevereiro de 2007.

4. Sato M, Jaber M, Silva R, Quadros I, Alves ML. Mapeando os territórios e identidades do Estado de Mato Grosso, Brasil. Cuiabá: EdUFMT; 2013.
5. Mendes ABV, Ferreira LC. Conservação ambiental e direitos multiculturais. UAKARI. 2009;5(2):19-31.

6. Santos M. Território: globalização e fragmentação. São Paulo: Hucitec; 2006.

7. Moreno G. Terra e poder em Mato Grosso: política e mecanismos de burla 1892-1992. Cuiabá: EdUFMT; 2007.

8. Pignatti MG. As ONGS e a política ambiental nos anos 90: um olhar sobre Mato Grosso. São Paulo: Annablume; 2005.

9. Diegues ACS. O mito moderno da natureza intocada. São Paulo: HUCITEC; 1998.

10. Brasil. Lei $\mathrm{n}^{\circ} 9.985$, de 18 de julho de 2000. Regulamenta o art. 225, $\$ 1$ o, incisos I, II, III e VII da Constituição Federal, institui o Sistema Nacional 
de Unidades de Conservação da Natureza e dá outras providências. Diário Oficial da União, Brasília, 19 de julho de 2000.

11. Brasil. Decreto n 5.758, de 13 de abril de 2006. Institui o Plano Estratégico Nacional de Áreas Protegidas - PNAP, seus princípios, diretrizes, objetivos e estratégias, e dá outras providências. Diário Oficial da União, Brasília, 17 de abril de 2006.

12. Honneth A. Luta por reconhecimento: a gramática moral dos conflitos sociais. São Paulo: Ed. 34; 2003.

13. Heidrich AL. Território, integração sócio espacial, região, fragmentação e exclusão social. In: Ribas AD, Sposito ES, Saquet MA, organizadores. Território e desenvolvimento: diferentes abordagens. Francisco Beltrão: Unioeste; 2004. p. 37-66.

14. Haesbaert R. Concepções de território para entender a desterritorialização. In: Santos M, Becker BK, Silva CAF, Gonçalves CWP, Limonad E, Almeida FG et al, organizadores. Território, territórios: ensaios sobre o ordenamento territorial. 3. ed. Rio de Janeiro: Lamparina; 2011. p. 43-71.

15. Habermas J. Consciência moral e agir comunicativo. Rio de Janeiro: Tempo Brasileiro; 1989. (Estudos Alemães. Biblioteca Tempo Universitário, 84).

16. Rivera FJU. Agir comunicativo e planejamento social: uma crítica ao enfoque estratégico. Rio de Janeiro: Fiocruz; 1995.

17. Heidemann FG. Do sonho do progresso às políticas de desenvolvimento. In: Heidemann FG, Salm JF, organizadores. Políticas Públicas e desenvolvimento: bases epistemológicas e modelos de análise. 2. ed. Brasília: Editora Universidade de Brasilia; 2010. p. 23-40.

18. Serres M. O contrato natural. Rio de Janeiro: Nova Fronteira; 1991. (Coleção Nova Fronteira Verde)

19. Pignatti MG, Barsaglini RA, Senna GD. Envelhecimento e rede de apoio social em território rural do Pantanal matogrossense. Physis. 2011;21(4):1469-91. http://dx.doi.org/10.1590/S0103-73312011000400016.

20. Marques AIM. Lugar do modo de vida tradicional na modernidade. In: Oliveira AU, Marques AIM, organizadores. O campo no século XXI: território de vida, de luta e de construção da justiça social. São Paulo: Editora Casa Amarela; 2004.
21. Leonardi VPB. Entre árvores e esquecimentos: história social nos sertões do Brasil. Brasília: Paralelo 15 Editores; 1996.

22. Pignatti MG, Yokoo EM, Castro SP, Bastos W. Saúde e Ambiente: lugar da doença e doença do lugar na população do entorno da RPPN SESC Pantanal. In: Atanaka-Santos M, Pignatti MG, Chaves AL, organizadores. Questões ambientais em Saúde Coletiva. Cuiabá: EdUFMT; 2012. p. 25-50.

23. Santos BS, Chaui M. Direitos humanos, democracia e desenvolvimento. São Paulo: Cortez; 2013.

24. Castro CA, Cunha CN, Callil CT, Couto EG, Nogueira FMB, Guarim-Neto G, et al. Dez Anos de Pesquisas de Longa Duração no Pantanal Norte: Achados, Lições e Perspectivas. In: Tabarelli M, Rocha CFD, Romanowski HP, Rocha O, Lacerda LD, editores. PELD - CNPq: dez anos do Programa de Pesquisas Ecológicas de Longa Duração do Brasil: achados, lições e perspectivas. Recife: Ed. Universitária da UFPE; 2013. 446 p. (Série de Publicações PELD).

25. Brasil. Conselho Nacional Pesquisa. PELD: Programa Ecológico de Longa Duração [Internet]. [citado em 2014 set 25 ]. Disponível em: www.cnpq/ peld

26. Pignatti MG, Castro SP, Quadros IP, Albernaz-Silveira R. Água na gente e gente na água: o caminho das águas em São Pedro de Joselândia. Cuiabá: EdUFMT; 2007.

27. Laabs V, Amelung W, Pinto AA, Wantzen M, Silva CJ, Zech W. Pesticides in surface water, sediment, and rainfall of the Northeastern Pantanal Basin, Brazil. J Environ Qual. 2002;31(5):1636-48. http://dx.doi.org/10.2134/ jeq2002.1636. PMid:12371181.

28. Silva EA. Água de consumo humano: escassez na abundância e contaminação microbiológica nos períodos de cheia e seca Pantanal de MT [dissertação]. Cuiabá (MT): Universidade Federal de Mato Grosso; 2007.

29. Porto MFS. Uma ecologia política dos riscos: princípios para integrarmos o local e o global na promoção da saúde e da justiça ambiental. Rio de Janeiro: Editora Fiocruz; 2012. 270 p.

30. Sen AK. A desigualdade reexaminada. Rio de Janeiro: Record; 2001.

Recebido em: Jun. 10, 2015 Aprovado em: Dez. 09, 2015 